\title{
A construção da identidade e os regimes de visibilidade dos povos indígenas na universidade
}

\section{The construction of identity and the regimes of visibility of indigenous peoples at the university}

\section{Maria José GUERRA*}

UEL

\section{Wagner Roberto do AMARAL ${ }^{* *}$}

$U E L$

Resumo: Abordamos nesse texto a educação superior indígena - temática recente no cenário nacional - sob um olhar que vai um pouco além do descritivo para tentar dar conta de uma reflexão sobre os significados construídos nos percursos percorridos pelos acadêmicos indígenas do Brasil, especialmente no caso dos da região norte do Paraná. Os elementos históricos aqui descritos exercem um duplo papel: são parte da positividade necessária aos estudos das áreas de Ciências Sociais Aplicadas e também são alvo de uma leitura que pretende discutir quais são essas significações e esses valores envolvidos nos fatos dessa história recente. Muitos dos dados aqui analisados foram coletados no período de agosto de 2013 a março de 2014 por professores e estudantes indígenas e não indígenas da Universidade Estadual de Londrina, que desenvolvem projeto de extensão visando à análise dos currículos das escolas indígenas localizadas nas terras indígenas da região norte do Paraná. Foram utilizadas, ainda, referências produzidas a partir de pesquisa realizada junto a acadêmicos indígenas matriculados nas universidades estaduais do Paraná.

Palavras-chave: Identidade. Escola indígena. Educação superior indígena. Semiótica da cultura.

\begin{abstract}
We approach in this text indigenous higher education - recent issue on the national scenario - under a point of view a little beyond the descriptive to try to account for a reflection on the meanings constructed in the paths covered by indigenous scholars from Brazil, especially in the case of northern Paraná. The historical elements described here play a dual role: they are part of the positivity necessary to study the areas of Social Sciences and are also subject to a reading that discusses what those meanings and values involved in the facts of this recent history are. Much of the data analyzed here were collected from August 2013 to March 2014 by teachers and indigenous and non-indigenous students at the State University of Londrina, who develop extension project aimed at analyzing the curricula of indigenous schools located on indigenous lands in the region northern Paraná.
\end{abstract}

Keywords: Identity. Indian School. Indian higher education. Semiotics of culture.

\author{
* Doutora em \\ Linguística. \\ majogue@uol.com.br \\ ** Doutor em \\ Educação. \\ wramaral2011@ \\ hotmail.com
}




\section{Introdução}

A presença dos povos indígenas nas Universidades públicas brasileiras é uma realidade deste novo século. Há inúmeras Instituições de Ensino Superior públicas que, por uma série de possibilidades de ingresso e permanência diferenciados, vinculados a políticas de ações afirmativas (cotas, vagas suplementares, vestibulares específicos, dentre outros), recebem estudantes indígenas das mais variadas etnias nas mais diversas regiões do Brasil.

No estado do Paraná, o ingresso e permanência de indígenas no ensino superior ocorreu, ineditamente no país, por meio da Lei n ${ }^{\circ} 13.134 / 2001$, alterada pela Lei n. 14.995/2006, que prevê aos povos indígenas residentes em território paranaense o direito de frequentar uma Instituição de Ensino Superior (IES), através de vagas suplementares e ingresso específico. A referida lei foi sancionada em 18 de abril de 2001, prevendo inicialmente três vagas para cada uma das Universidades Estaduais do Paraná. Em 2006, a lei foi alterada, garantindo seis vagas suplementares para cada Universidade Estadual paranaense. Emergiu então o primeiro desenho institucional de política pública de educação superior indígena no país, seguido de outros formatos em diferentes universidades públicas e confessionais no Brasil. A legislação garantiu também aos acadêmicos indígenas o direito a uma bolsa auxílio cujo valor foi progressivamente elevado ao longo da década (AMARAL, 2010).

A partir dessas orientações legais, o estado do Paraná recebe, em todas as universidades estaduais e também na Universidade Federal do Paraná (UFPR), estudantes de várias etnias. Neste trabalho, abordaremos objetivamente dados observados durante a trajetória cotidiana vivenciada pelos acadêmicos indígenas na Universidade Estadual de Londrina (UEL), acompanhadas pela Comissão Universidade para os Índios (CUIA) ${ }^{1}$ desta Instituição, bem como pelos projetos de ensino, pesquisa e de extensão ${ }^{2}$ desenvolvidos, que contam com a participação desses sujeitos; porém, sempre situando o objeto particular no contexto geral das relações históricas que marcam não só a cidade, as aldeias indígenas mas, sobretudo, o contexto nacional. Nesse sentido, revelam-se denominadores comuns de norte a sul do país. Há sentimentos constitutivos de nossa nacionalidade. Há um desconfortável caráter multiétnico cravado na identidade brasileira, cuja presença dos povos indígenas é inegável.

As análises presentes nesse trabalho inspiram-se, desta forma, nos percursos realizados pelos estudantes indígenas no universo do ensino superior e nas relações institucionais que passam a ser construídas, decorrentes de sua emblemática, simbólica e resistente presença nesse espaço.

${ }^{1}$ A Comissão Universidade para os Índios (CUIA) foi instituída pela Secretaria de Estado de Ciência, Tecnologia e Ensino Superior do Paraná (SETI) por meio da Resolução Conjunta n. 006/2007, sendo uma Comissão de caráter permanente e interinstitucional com a finalidade de viabilizar acompanhar o ingresso, permanência e conclusão dos estudantes indígenas nas Universidades públicas do Paraná. Cada Universidade possui uma CUIA (denominada CUIA local) que indica três representantes para compor a CUIA Estadual, esta última vinculada à SETI.

${ }^{2}$ Na UEL estão sendo desenvolvidas atualmente cinco ações que envolvem os estudantes indígenas nesta instituição: o "Programa de Formação Intercultural”, voltado ao acompanhamento pedagógico dos estudantes indígenas nos diferentes cursos em que estão matriculados; o Projeto "Bilinguismo e a presença indígena na Universidade: uma troca de saberes" voltado ao acompanhamento específico de estudantes indígenas bilíngues; o Projeto de Pesquisa "A trajetória formativa dos estudantes Kaingang e Guarani na Universidade 


\section{Nós e eles, medo e vergonha, identidade e alteridade}

A análise do modo de presença dos alunos indígenas nas universidades brasileiras nos obriga a recorrer a questões linguísticas e antropológicas anteriores. São elementos essenciais para que se entenda como a presença desses estudantes está comprometida com raízes culturais profundas que não podem ser apagadas apenas porque, nesse momento, a sociedade está possibilitando o acesso ao ensino superior. Todo esse contexto está ligado a um sistema de valores simbólicos que assegura as relações de pertencimento e estabelece o modo de ser e de sentir próprios de cada sociedade. A Semiótica da Cultura desenvolvida pela Escola Soviética nos oferece alguns conceitos úteis para que se possa compreender um pouco mais todas essas relações.

A Semiótica Soviética, seguindo as propostas da Antropologia, entende a cultura como um sistema de limitações impostas pela sociedade ao comportamento do homem; "a função natural cede lugar à cultural." (LÓTMAN et al., 1981, p. 237). A mesma afirmação de Lótman et al. encontra eco na antropologia simbólica, quando esta propõe que o controle biológico do homem vai se tornando cada vez mais simbólico e dependente de fatores culturais.

Seguindo esses pressupostos, a Semiótica, por seu turno, propõe que a cultura modeliza, impõe um molde ao modo de ser, agir e pensar, por isso formaliza as significações simbólicas traçadas pela cultura também do ponto de vista da psicologia social, das paixões coletivas. As significações são erguidas abraçando todos os domínios da vida social. Nada que se refira à linguagem é inocente, desprovido de sentido social. Assim, no imaginário social, duas esferas do domínio do sensível se estabelecem e passam a direcionar os caminhos simbólicos: uma regulada pelo medo; e outra, pela vergonha. A partir dessas esferas, Lótman et al. (1981, p. 237-240) prossegue expondo que, na sociedade, a divisão de um grupo organizado pelo medo e outro pela vergonha "coincide com a antítese 'nós-eles'.

Os pronomes são elementos da língua que desempenham um papel essencialmente lógico-gramatical, isto é, possuem função muito mais estrutural e referencial, do que propriamente lexical - não são os significados, as ideias construídas em cada palavra, que estão a cargo do pronome, mas as articulações e conexões que as ideias comportam. Os pronomes organizam o discurso em relação à enunciação que o produziu, por isso, além das determinações lógicas, o discurso sofre também determinações de ordem do sensível.

O tipo de limitações demarcada ao nós e ao eles são profundamente diferentes. O nós socializado, cultural, marca o pertencimento, a inclusão, trata-se de uma coletividade na qual imperam as normas da honra e da vergonha. Entre os pares de uma comunidade não se admite aquilo que nos possa envergonhar.
Estadual de Londrina e na Universidade Estadual de Maringá e a constituição de circuitos de trabalho indígena" com o objetivo de analisar os percursos feitos por profissionais indígenas formados pelas Universidades Estaduais do Paraná; o Projeto de Extensão "A escola indígena e seu currículo: lugar de pertenças e de identidades”, voltado à assessoria às escolas estaduais indígenas da região norte do Paraná especificamente à sua organização curricular; e o Ciclo Intercultural de Iniciação Acadêmica de Estudantes Indígenas, um curso anual específico para indígenas ingressantes na UEL para complementar sua escolarização básica e sintonizálos ao universo acadêmico. 
Lótman et al. (1981) vai além e mostra que, na transição das épocas pré-histórica, na composição do universo cultural pelos homens, era necessário um mecanismo distinto do mundo dos animais, as sociedades humanas procuravam algo diferente do medo, este sim presente em todas as espécies de animais, não apenas no homem. A vergonha é essencialmente humana e as transformações na constituição dos parâmetros culturais foi por ela guiada. Daí em diante, entre vergonha e medo se estabelece uma oposição e uma complementariedade. Na esfera do nós coletivo, a vergonha passa a regular as ações até o ponto de "sentir vergonha por estar com medo”. Na intimidade do nós cabe apenas a honra e a vergonha, não se trata do lugar do medo. O medo rege as relações com o eles, aqueles que estão fora de mim: o outro, o estranho.

A denominação que os Kaingang, uma das etnias que habitam a Bacia do Rio Tibagi no norte do Paraná, dão aos europeus e mestiços comprova essa presença do medo. Desde o século XIX, há inúmeros conflitos sangrentos com a invasão dos territórios indígenas por colonizadores não indígenas em busca da posse da terra. Os Kaingang chamam os não-índios de fog, há uma referência à palavra fogo, ao estranho, ao perigo.

De outra parte, os brasileiros não-índios, sempre posicionam os povos indígenas como eles - os índios. São os que se opõem, os que lutam pela demarcação de terras numa história de conflitos, medos e lutas. Assim, temos o medo também como categoria sensível constitutiva da identidade cultural brasileira.

Entretanto, essa arqueologia das diferenças socioculturais ainda está presente nas relações sociais do mundo da modernidade, porém, com a globalização e as transformações rumo à pós-modernidade, novos contornos vão também moldando as relações no universo global de mercado. Novas categorias vão se sobrepondo às categorias essenciais e novos desafios vão sendo traçados. O nós e o eles, o medo e a vergonham são organizados agora em torno de um mundo globalizado, no qual há o embate entre a identidade e a alteridade. Os modos de presença do outro precisam ser condicionados pelo espetáculo global.

A identidade só se constrói a partir do outro, tudo funciona tal qual os mecanismos do pronome: eu só sou eu porque há um outro, há um tu a quem eu tomo por referência para demarcar os limites da minha presença. A identidade emerge, necessariamente, mediada pela alteridade. Configura-se um jogo entre identidade e diferença e a presença do outro é, ao mesmo tempo, incômoda e necessária para demarcar os limites do nós.

Diante dos limites do nós e do eles, antes mesmo de iniciarmos algumas análises propriamente ditas sobre os estudantes indígenas no ensino superior, é preciso lembrar que a história dos povos indígenas, particularmente no norte do Paraná, é traçada na história do Brasil pelo medo. Há séculos, a relação com o outro - povos indígenas X invasor europeu - sempre 
foi marcada pela violência, pelo medo. No entanto, também pela vergonha. Se assumimos o caráter multiétnico da identidade brasileira e tivermos os povos indígenas, ibéricos e africanos como base dessa identidade, instaura-se, então o nós; desta vez susceptível de vergonha perante a história pontuada de massacres. Assim, a presença indígena na universidade torna mais visível as inoportunas paixões do medo e da vergonha intrínsecas às nossas relações históricas.

\section{A identidade e o pertencimento dos povos indígenas}

A leitura do trabalho de Gersem dos Santos Luciano, liderança e pesquisador da etnia Baniwa (2006, p. 28-32) mostra o percurso traçado pela construção da identidade dos povos indígenas no Brasil. A denominação índio surge porque a Coroa Espanhola no século XV estava preocupada em chegar à Índia. Não há índios porque não há nenhum povo índio, nenhuma etnia denominada índio ou indígena; há Guarani, Tupinambá, Bororo, Xavante, Xokleng e tantas outras etnias presentes no Brasil. Assim, "cada índio pertence a um povo” (LUCIANO, 2006, p. 30).

A organização dos movimentos sociais indígenas a partir da década de setenta do século XX tornou a questão de identidade cada vez mais decisiva nas questões relativas à compreensão do papel das populações indígenas na história brasileira. A leitura do texto de Gersem Baniwa mostra um movimento bastante conhecido em antropologia: de como as identidades e diferenças podem levar à unidade. Para o autor, a denominação índio dada pelos colonizadores fez crescer, do ponto de vista retórico, duas imagens distintas. Por um lado, o índio como termo pejorativo, como aquele que é selvagem, preguiçoso, traiçoeiro, aproveitador. Por outro lado, uma imagem romântica, quase infantil, o bom selvagem de inspiração em Rousseau que luta em defesa das matas e da natureza.

Como se pode observar, o campo simbólico bipartido traçado sob o ponto de vista dos colonizadores, leva as diferenças significativas próprias de cada etnia a serem diluídas por categoria estranhas à natureza cultural peculiar de cada povo. Tudo é nivelado pela oposição. Por outro lado, a mesma categoria que homogeneíza, ao ser apropriada pelos próprios indígenas como sujeitos coletivos, históricos e políticos, passa a revelar e posicionar sua capacidade de organização, luta e resistência.

[...] era importante manter, aceitar e promover a denominação genérica de índio ou indígena, como uma identidade que une, articula, visibiliza e fortalece todos os povos originários do atual território brasileiro e, principalmente, para demarcar a fronteira étnica e identitária entre eles, enquanto habitantes nativos e originários dessas terras, e aqueles com procedência de outros continentes, como os europeus, os africanos e os asiáticos. (LUCIANO, 2006, p. 30) 
No texto de Gersen Baniwa está instalado o nós e o eles: por um lado, há diferenças éticas profundas entre os povos que são os genuínos habitantes do que hoje está demarcado como território brasileiro; por outro lado, a marca do pertencimento à terra foi uma identidade poderosa capaz de construir uma unidade. Assim, foram as identidades e diferenças que levaram a uma unidade construída como respostas às violências de um Outro que se apresenta como intimidador e violento - o invasor europeu.

Os povos indígenas chegaram à conclusão de que era preciso criar uma identidade política coesa e unitária que, mesmo não estando presente na origem étnica de cada povo, fosse forte o suficiente para enfrentar uma alteridade extremamente pautada pelo medo. Antes da presença dos portugueses (do outro) não havia indígenas, não há povo índio; porém, é fundamental criar, aceitar e manter uma nova identidade multiétnica determinando quem são os verdadeiros povos do Brasil. É precisamente esta identidade que vai se constituir como uma marca de pertencimento forte o suficiente para suscitar os mais autênticos sentimentos de honra e fraternidade. Aqueles que antes, porventura, possuíam conflitos interétnicos históricos são agora fraternos, “parentes”. Como esclarece Gersen Baniwa, houve a criação de uma nova identidade multiétnica sintetizada no termo fraterno "parente”. Nesses termos, o autor (2006, p. 31) nos explica que:

O termo parente não significa que todos os índios sejam iguais e nem semelhantes. Significa apenas que compartilham de alguns interesses comuns, como os direitos coletivos, a história de colonização e a luta pela autonomia sociocultural de seus povos diante da sociedade global. Cada povo indígena constitui-se como uma sociedade única, na medida em que se organiza a partir de uma cosmologia particular própria que baseia e fundamenta toda a vida social, cultural, econômica e religiosa do grupo. Deste modo, a principal marca do mundo indígena é a diversidade de povos, culturas, civilizações, religiões, economias, enfim, uma multiplicidade de formas de vida coletiva e individual.

A obra de Gersen Baniwa nos esclarece esse percurso traçado pela construção da identidade dos povos indígenas no Brasil contemporâneo. O autor, nesta perspectiva, analisa a denominação caboclo nessa trajetória e mostra um momento de negação da identidade étnica por fortes pressões do preconceito social: a negação da identidade em função do outro, do medo do outro. Naquele momento ser caboclo era um significado construído pelo medo de ser Baniwa, Ianomâmi, Kaingang, Guarani ou até mesmo índio.

Além disso, se os povos indígenas reivindicavam a condição de ser brasileiro, se era reivindicado o pertencimento, ser Ianomâmi, ou até mesmo índio, entre os iguais, entre o nós brasileiros, causaria vergonha. Entre o nós, ser índio causa vergonha. Ser índio é ser preguiçoso, ou romântico inadequado, na melhor das hipóteses. 
Quando, nos anos setenta, frente à crise de identidade e alteridade, os povos indígenas constituem uma nova identidade multiétnica por meio da sua mobilização e da criação das organizações indígenas, não há mais do que sentir vergonha por ser índio. Um outro nós aparece agora forte para enfrentar o Outro: agora somos “parentes”. A denominação parentes firma um pertencimento, um nós claro; aqueles que antes eram guerreiros rivais movidos pelo medo são agora parentes movidos pela honra e pelo sentimento de vergonha entre os meus pares. Será que o termo não romantiza demais e oculta os conflitos e diferenças interétnicas ainda existentes?

Este jogo entre nós e eles pode nos levar a uma outra reflexão também esclarecedora desse processo de construção de identidade dos povos indígenas no mundo contemporâneo. Stuart Hall (2003) nos lembra que a construção do sujeito do século XXI, na modernidade tardia, constrói um sujeito desconexo, que não tem identidade fixa; é o que o autor chama de fragmentação das identidades. Os percursos trilhados pelos acadêmicos indígenas no ensino superior há pouco mais de uma década no Paraná revelam, para além do conflito identitário evidenciado por esses sujeitos no espaço da Univer-cidade (AMARAL, 2010), uma capacidade de resistência e de afirmação de suas identidades étnicas diante do contraste com o Outro.

\section{Identidade e pertencimento nas universidades - caso do norte do Paraná}

Os povos Kaingang e Guarani, distintos grupos étnicos presentes no território brasileiro e paranaense, estão situados demograficamente dentre os povos com maior densidade populacional indígena no Brasil. Compõem o conjunto de diversidades e especificidades presentes entre os povos indígenas no Brasil, atualmente pertencentes, reconhecidos e organizados em 305 etnias, falantes de 274 línguas diferentes, segundo dados do Censo de 2010.

Parte dessa diversidade étnica se revela no Paraná por meio das expressões, organizações e modos de vida Kaingang, Guarani, Xokleng e Xetá, distribuídos no território paranaense - ocupado e reocupado por esses grupos antes e durante o processo de colonização não indígena, sendo este um fenômeno de conquista e resistência presente até a atualidade (TOMMASINO; FERNANDES, 2001; ALMEIDA; MURA, 2003).

O processo de redução, delimitação e demarcação das terras indígenas em reservas ou áreas indígenas, conduzido sob intervenção do Governo Federal e dos Governos do Estado do Paraná a partir das décadas de 1930, foi motivado, fundamentalmente, pela ofensiva entrada e expansão das empresas capitalistas no processo de colonização do norte paranaense. Essa expansão, empreendida para disseminar e ocupar o mitológico vazio 
demográfico (MOTA, 1994), provocou e ainda provoca significativas mudanças nas dinâmicas socioculturais e políticas nos grupos étnicos presentes e resistentes neste território.

Essas mudanças, expressadas pela preservação, ruptura ou ressignificação de rituais, costumes, valores, linguagens e relações políticas e culturais próprias, constituem-se historicamente distintas para os povos Kaingang e Guarani no Paraná, em cada terra indígena. Diferentes também são os seus processos e movimentos de resistência considerando, inclusive, as relações interétnicas de alianças e conflitos entre estes grupos diante das intervenções dos Governos Federal, Estadual e Municipais, e de organizações religiosas e não governamentais em seus territórios.

Apesar de constituírem comunidades etnicamente diferentes e organizarem-se politicamente de forma distinta da dos povos indígenas das regiões Norte, Nordeste e Centro-oeste do país - observadas, principalmente, as duas últimas décadas de organização do movimento indígena no Brasil (LUCIANO, 2006) -, os povos Kaingang e Guarani habitantes do território paranaense se articulam nas organizações indígenas circunscritas ao Paraná e na região sul do país para discutir, reivindicar, negociar e propor políticas públicas voltadas às áreas da saúde, educação, agricultura, demarcação territorial, dentre outras.

As presenças e manifestações políticas desses povos e suas comunidades expressam suas características culturais, cosmológicas, mitológicas, político-faccionais, linguísticas próprias e recentemente passam a ocupar, de forma visível ou invisível, o espaço acadêmico por meio dos estudantes indígenas universitários.

A delimitação de dois campos de visibilidade - o nós e o eles - é levada para dentro das Universidades. Não apenas a UEL, mas todas as demais Instituições Estaduais de Ensino Superior do Paraná e também a UFPR recebem estudantes indígenas das terras indígenas localizadas no território paranaense e a presença desses alunos continua obedecendo ao mesmo regime de invisibilidade a que estavam submetidos até o Ensino Médio nas escolas públicas que frequentaram. É como se a escola estadual de ensino fundamental e médio que frequentaram nos municípios paranaenses de pequeno porte como Santa Amélia, Guapirama, São Jerônimo da Serra, Tamarana, ou outras de proporções semelhantes, estivessem se estendendo até os bancos universitários. Trata-se dos alunos que não-devem-ser-vistos. São, como explicitaremos mais adiante, as não-presenças dos alunos. A presença só se torna efetivamente presença quando começa a significar, ou seja, quando a diferença começa a fazê-lo ocupar uma significação no espaço. São alunos cuja diferença sempre foi camuflada pela presença quase invisível, desqualificando-os como sujeitos da aprendizagem.

Ao analisar os percursos dos acadêmicos indígenas no ensino superior, Amaral (2010, p. 358) destaca os preconceitos cotidianos vivenciados 
por esses sujeitos, sendo reflexo continuado das trajetórias trilhadas por eles nas escolas públicas. Isso fica explícito no relato de um estudante indígena entrevistado ${ }^{3}$ :

Isso, na verdade, era uma das dificuldades que eu tinha na cidade, não me sentia em casa. [...] eu era o único indinho na sala. Estudava no meio de tantos alunos não índios que estudavam lá. Eu tinha medo assim [...] tinha já essa noção do preconceito, da aceitação, de que alguém me aceitasse lá do jeito que eu era, eu sendo índio ou não. Aí, eu me isolava, eu pegava e sentava na última cadeira. Lembro que, nesse período, eu fiz amizade com um colega só nessa escola. Ele ia em casa, a gente brincava, conversava, saía nadar nos rios. Um colega só durante esse período que fiquei na cidade. Trabalhos eu tinha que fazer sozinho, então... [...] via eles rindo de mim e, às vezes, a professora perguntava para mim, não sabia responder direito, tinha vergonha, eu me engasgava, tudo... Aí, né, eles começavam a rir, a fazer algumas brincadeirinhas e aí, nessas partes que eu me sentia um pouco mal [...] A professora, na verdade, às vezes, nem notava que estava ali, na verdade, que tinha um índio ali, estudando, ela nem notava. Então, para ela era tudo da cidade (L.V.S.).

O relato explicita que o preconceito passa a ser construído ao longo do processo de escolarização dos estudantes indígenas universitários, fundamentalmente, no contato e acesso à escola fora da aldeia. Segundo Lima e Barroso-Hoffman (2007, p. 15),

Na sua maior parte, os jovens indígenas que cursam o ensino médio o fazem com grandes sacrifícios pessoais e de suas famílias, sofrendo grande discriminação e, o que é muito próprio das áreas próximas às terras indígenas, um tipo peculiar de invisibilidade que os torna pouco perceptíveis aos olhos de professores e diretores de escolas que, sem necessariamente agirem de má-fé, mas imbuídos dos preconceitos intensos dessas regiões, tomam-nos por "caboclos” pouco letrados.

Ao analisar as diferentes formas de manifestação do preconceito étnico, Roberto Cardoso de Oliveira (2006, p. 42-43) analisa as categorias nativas de "caboclo" e "bugre” presentes nos discursos dos não indígenas e principalmente dos indígenas, consideradas por ele como "sintomas dos sistemas de exploração econômica e de dominação política que segmentos regionais da população brasileira exerciam - e em muitas regiões ainda exercem - sobre os povos indígenas”.

Caracterizando essas expressões como resultantes das "áreas de fricção interétnica”, o autor as associa ao conceito de "consciência infeliz” ou de identidade alienada, incorporada e manifestada pelos próprios indígenas como consequência da histórica negação da sua identidade indígena pelo Estado e pela sociedade não-índia, principalmente antes da emergência do movimento indígena em escala nacional. Ao referenciar a pesquisa realizada junto ao povo Tukúna afirma que,
${ }^{3} \mathrm{O}$ entrevistado L.V.S. foi aluno do curso de Artes Visuais, após transferência do curso de Medicina da Universidade Estadual de Londrina. Ingressou na UEL no ano de 2004 e não concluiu sua graduação devido ao seu óbito no ano de 2013. Sua entrevista é parte da pesquisa de campo realizada por ocasião da elaboração de tese de doutorado de Amaral (2010), e foi devidamente autorizada pelo sujeito entrevistado por meio de Termo de Consentimento Livre e Esclarecido, que consta como anexo do referido trabalho. 
O caboclo pode ser visto [...] como o resultado da interiorização do mundo do branco pelo Tukúna, dividida que está em sua consciência em duas: uma voltada para os seus ancestrais, outra para os poderosos homens que circundam. O caboclo é, assim, o Tukúna vendo-se a si mesmo com os olhos do branco, isto é, como intruso, indolente, traiçoeiro, enfim, como alguém cujo único destino é trabalhar para o branco. Parafraseando Hegel, poder-se-ia dizer que o caboclo é própria “consciência infeliz”. Fracionada sua personalidade em duas, ela bem retrata a ambiguidade de sua situação total. (CARDOSO DE OLIVEIRA, 1964, p.80)

Como reflexo da sociedade, os preconceitos contra os indígenas são manifestados no ambiente escolar e no espaço acadêmico, sendo por eles incorporados ou deles exigindo estratégias de sobrevivência ou resistência. Cavalcante (2009, p. 105) também reflete sobre o fenômeno do mimetismo ao associá-lo aos conhecimentos escolares que passam a ser ensinados e aprendidos pelos indígenas como forma de trânsito para "tornarem-se brancos”.

Nesses casos, a fronteira que há entre o "Eu” e o “Outro”, no que diz respeito ao processo de construção da educação escolar, traduz-se na forma de mimetismo. Um movimento recorrente em muitos grupos indígenas das terras baixas sul-americanas, que foi identificado por Kelly (2005) como o processo de "virar branco". Nesse processo, as afirmações: "agora somos civilizados”, para justificar os resultados de algum serviço público, ou "aprender língua portuguesa e matemática para fazer negócios e assinar documentos”, para argumentar sobre a importância do acesso do mesmo serviço, são extremamente significativas para clarear o significado cotidiano das relações que esses mesmos grupos têm com os "brancos” e o Estado (KELLY, 2005). [...] partem da crença de que, ao acessarem os conhecimentos da sociedade não indígena, lhes estariam necessariamente garantidos os direitos de trânsito nessa mesma sociedade ou garantido o "processo de virar branco".

Amaral (2010) destaca ainda que a timidez e a insegurança dos estudantes indígenas em se manifestar se apresenta, sobretudo, na relação de escolarização junto aos não indígenas na escola da cidade ou na universidade, fazendo referência inversa quando estudavam na escola da aldeia. Atenta-se para o fato de que sua autoimagem de mal escolarizado e de aluno com baixo desempenho escolar se revela, para ele próprio, na relação direta com o não indígena, bem como pelas constantes afirmações adjetivadas por este último acerca do que representa ser índio, haja vista os frequentes e perversos estereótipos associados à vadiagem, à sujeira, à bebedeira, dentre outros (LUCIANO, 2006).

É possível que, para o estudante indígena, a imagem inversa do aluno indígena incapaz, tímido e com baixo desempenho escolar seja a do aluno não-índio, branco, residente na cidade, com exímio desempenho 
escolar e com ótima fluência na sua língua. Essa imagem pode ser resultado das históricas imagens construídas acerca dos povos indígenas no Brasil, desde o contato com os portugueses nesse território, ainda disseminadas e visibilizadas no ambiente escolar.

Os estudantes indígenas cursam os primeiros anos do Ensino Fundamental em escolas indígenas localizadas na terras indígenas, cujo Projeto Político Pedagógico (PPP) se assenta em princípios como bilinguismo e interculturalidade, devendo estabelecer normas diferenciadas na sua proposta pedagógica e curricular e na sua gestão; entretanto, quando nos aproximamos do cotidiano escolar vemos que as práticas e o discurso pedagógico nem sempre seguem as orientações preconizadas pela legislação da Educação Escolar Indígena no Brasil, tampouco nos citados PPPs.

Na tarefa de analisar os currículos e PPPs das escolas estaduais indígenas da região norte do Paraná por meio de projeto de extensão desenvolvidos pela UEL (já referido nesse trabalho), encontramos, por exemplo, em uma das escolas indígenas visitadas um painel com as letras do alfabeto presentes nas palavras da língua indígena local. Nesse painel, a letra $w$ - baste comum em várias palavras da língua indígena aprendida na escola local - estava representada pela palavra do inglês wafers, culturalmente tão distante da vida ali presente. Em outra sala de aula, essa mesma letra estava representada por um desenho do personagem Wolverine, do filme norte-americano X-Man. Em outra escola indígena identificamos no alfabeto a letra $k$ representada pelo boneco Ken, num desenho que o coloca de braços dados com a boneca Barbie.

Sendo a escola indígena um espaço de contradições, produções, reproduções, ocultamentos e afirmações e, fundamentalmente, um espaço de poder, esses portadores de texto disputam espaços com outros textos e símbolos que expressam o fortalecimento de elementos das culturas Kaingang e Guarani, revelando a importância e a necessidade da formação continuada dos profissionais de educação vinculados a essas escolas, junto com lideranças dessas comunidades. A atuação da equipe de extensão da UEL tem sido a de identificar esses elementos de afirmação e de (in)visibilidades e refletir sobre eles com os coletivos pedagógicos das escolas indígenas, com as lideranças e acadêmicos indígenas, nas seis terras indígenas da região norte do Paraná ${ }^{4}$.

Os meios de comunicação, a internet, as relações mercantis que se impõem na vida cotidiana, fazem com que as relações de pertencimento sejam revistas e recontadas. Desde o ensino fundamental, os limites entre o nós e o eles vão sendo testados e as identidades redesenhadas ao longo da história.

Um autor que pode nos auxiliar a refletir sobre essa questão dos limites da identidade é o cientista francês Eric Landowski (2002). A obra Presenças do Outro - ensaios de sociossemiótica nos aponta algumas
${ }^{4}$ Terra Indígena de Apucaraninha, Terra Indígena de S. Jerônimo, Terra Indígena de Barão de Antonina, Terra Indígena de Laranjinha, Terra Indígena de Pinhalzinho e Terra Indígena Ywy Porã ou Posto Velho. 
balizas para que se possa analisar essa presença indígena nas Universidades públicas. O capítulo "Busca de Identidade, Crises de Alteridade” (2002, p. 3-25), dentre outros pontos abordados, faz uma análise dos significados envolvidos nos processos socioculturais de assimilação $\mathrm{X}$ exclusão no contexto da Europa do século XXI, especialmente na sociedade francesa. Se guardarmos certas diferenças de contextos, os processos que ocorrem na Europa entre colonizador e colonizados repetem-se aqui no Brasil de forma bastante semelhante.

Trata-se de um ensaio que fala da Europa, mas o Brasil constrói a própria identidade como colonizador nos moldes europeus, herdeiro direto e legítimo do salto mercantil ibérico. Além disso, a financerização das relações sociais e a hegemonia da sociedade de mercado impõem um padrão de conduta global homogêneo. Tudo isso nos faz bem próximos da visão etnocentrista do Velho Mundo. O desafio permanece: se elaborarmos uma leitura atenta do texto de Eric Landowski (2002), há grande possibilidade de estabelecermos uma relação extremamente especular entre ambas as relações colonialista: dos europeus com os imigrantes e, da mesma forma, da sociedade brasileira com os povos indígenas.

A Europa é um dos grandes centros imigratórios do mundo, para lá convergem pessoas das mais variadas partes do mundo, das mais variadas etnias. O artigo de Landowski (2002) fala sobre as relações entre o nós e o estrangeiro. Enfoca, particularmente, a questão francesa, mas acaba por traçar um panorama geral sobre como é tratada a diferença no mundo hegemônico do capital.

Nesses termos, é possível propor uma reflexão sobre como nós, representantes das instituições públicas brasileiras de ensino superior, nos posicionamos quanto às questões suscitadas pelas políticas afirmativas do Estado frente aos sérios problemas de educação que enfrenta o país. O mercado e o dinheiro como nexo social garantem semelhanças entre o que descreve o autor francês e a vida cotidiana na universidade paranaense.

O autor inicia afirmando que estar presente é fazer sentido. Assim, quando se observa o estudante indígena quase imperceptível, sentado calado ao fundo da sala de aula no campus na UEL ou noutra universidade, essa invisibilidade tenta reduzir esse aluno a uma quase insignificância. Entretanto, a presença indígena incomoda e, o que é mais espantoso, sobrevive a sucessivos massacres históricos: “de repente, o 'presente' se torna efetivamente presente, porque uma diferença começa a fazê-lo significar” (p. XII).

A diferença é constitutiva da identidade como nos expõe Landowski (2002): “O outro, porém, não é apenas o dessemelhante - o estrangeiro, o marginal, o excluído - cuja presença presumidamente incomodaria [...] É também o termo que falta, o complementar indispensável e inacessível.” 
(LANDOWSKI, 2002, p. XII). É precisamente nesse movimento pendular, contraditório, que se contextualizam os processos sociais e de assimilação $\mathrm{X}$ exclusão nas difíceis relações multiculturais, presentes também em nossa realidade.

Há um conjunto de comportamentos, aparentemente contraditórios, que combina assimilação, exclusão, ou mesmo uma dosagem das duas juntas, para que o grupo dominante possa manter um equilíbrio interno e preservar a hegemonia. É nessa perspectiva que vemos que, muitas vezes, as políticas públicas tornam-se projetos de assimilação, de modo a dar valor universal ao que é apenas local. As chamadas políticas de inclusão têm subentendido que todos são bem-vindos, desde de que se esforcem rapidamente para ser, agir e pensar como nós. Além da ajuda material que as instituições de assistência social fornecem aos estrangeiros e excluídos, o papel da escola é fundamental para que se consagre a metamorfose e, se esses recursos não são suficientes, o papel da escola é decisivo.

Assimilador, o grupo dominante abraça a todos, aparentemente generoso e democrático, dá lugar aos que lhe são estranhos, mas sempre taxando a diferença de, no mínimo, exótica e irracional. O outro é desqualificado como sujeito, suas singularidades são as diferenças que, além de assegurar a construção da identidade do assimilador, ao mesmo tempo garantem-lhe a posição superior e soberana frente ao diferente inferiorizado.

Neste panorama, os estudantes indígenas na universidade suscitam várias situações de conflito: se pelo lado do assimilador as políticas de inclusão são executadas como processos de assimilação; pelo lado dos alunos indígenas, o estranhamento, a falta de pertencimento e presença quase silenciosa, quase não-presença, tudo faz com que a distância e o sentimento de inadequação os torne cada vez mais estranhos. Segundo entrevista realizada por Amaral (2010, p. 403), destaca-se o relato de um estudante indígena ${ }^{5}$.

Mas eu sendo índio, eu me sinto estrangeiro, porque, pra mim, eu sou de um lugar diferente. Então, pra mim, eu sou um estrangeiro aqui. Eu percebo isso e os outros também. [...] Eu acho que é [comum os estudantes indígenas sentirem-se estrangeiros]. Na verdade, partindo de uma avaliação, assim, pessoal, nós índios, é... pra nós é novo entrar numa sociedade como essa, na faculdade. Pra nós, isso é novo, muito novo ainda. E até acostumar com isso, vai passar muito tempo, pra se acostumar com isso. Nós somos, na verdade... é o primeiro projeto nesse negócio, assim, de entrar na faculdade. Não tem muito tempo não. Não tem uns dez anos, não. Foi em 2001. Então, é novo ainda. Pra nós, ainda é uma novidade isso aí. Até para os que estão entrando agora, é novidade. Mas, daqui a 20, 30 anos, não vai ser novidade mais não (L.V.S).

\footnotetext{
${ }^{5}$ Entrevistado L.V.S. citado anteriormente nesse artigo, em nota de rodapé.
} 
É neste momento que as relações tornam-se mais tensas e as paixões mais conflitantes. A universidade, ao mesmo tempo em que oferece a possibilidade de uma nova identidade coletiva, do nós brasileiros, provoca a vergonha da diferença inferiorizada frente ao nós brasileiros; dessa forma, acaba por impor o medo e o retorno ao ele e à segregação.

\section{Considerações finais: “Minha avó morava aqui...”}

"Minha avó morava aqui." Esta frase foi dita por um estudante Kaingang no campus da UEL. Não há na frase nenhum sentido conotativo, nenhuma metáfora; ao contrário, trata-se de uma ideia referencial objetiva. No campus, exatamente no lugar de funcionamento do curso de Medicina Veterinária, os Kaingang, até o século passado, ali viviam, assim como habitavam em toda a região sul do país. Foram tirados com muita violência, por volta das primeiras décadas do século $\mathrm{XX}$, do lugar para abrigar ali o que é hoje a universidade, sendo uma extensão do espaço urbano ali constituído. No século XXI, as terras do norte do Paraná não são como nas grandes metrópoles do sudeste, onde o sangue indígena, há séculos, já foi virando pedra e asfalto. São mínimas as marcas de sangue indígena que ainda se pode perceber na Avenida Paulista em São Paulo, na Avenida Rio Branco no Rio de Janeiro, ou nas avenidas do centro urbano de Porto Alegre. No entanto, bem depois da Serra do Mar, o centro, o oeste, o norte ainda tem marcas de lutas recentes. Todo conflito coloca em embate o eu e o outro, mas não de forma aleatória; ao contrário, insere a diferença etnográfica no sistema de significações traçado pela história.

As significações sociais são traçadas pela história. As identidades e diferenças têm marcas históricas, por isso não se pode esquecer da origem colonial de nossa formação. Colonizador e colonizado estão na base da identidade multicultural do Brasil. O salto mercantil ibério ressoa até o século XXI nas nossas relações sociais que envolvem os povos indígenas. É esse o contexto em que devemos inserir a questão da educação superior indígena. As microrrelações que se estabelecem no cotidiano do campus da Universidade Estadual de Londrina reproduzem de modo particular as mesmas relações que se espalham por todo o território brasileiro. Trata-se de um outro incômodo, imprescindível em nossa identidade.

O elemento novo, vivo e presente nesse espaço passa a se constituir sujeito e a se denominar estudante indígena. Sujeito de resistência, sua presença se apresenta incômoda diante da história de massacres e etnocídios para que se instaurassem os "marcos civilizatórios" ocidentais, cristãos, homogeneizadores, capitalistas que, ainda, de forma hegemônica, se sustentam. A presença indígena na universidade ela própria já é sinal de resistência e de memória. Desafia a própria universidade a 
se transformar, a reconhecer e a dialogar com as diferentes e desiguais presenças e saberes existentes naquele espaço e fora dele. Desafio que se faz pela presença e pela continuidade de seguir (n)esse caminho.

\section{Referências}

ALMEIDA, Rubem Thomaz; MURA, Fabio. Guarani Kaiowa e Nhandeva. In: INSTITUTO SOCIOAMBIENTAL. Enciclopédia povos indígenas no Brasil. 2003. Disponível em: http.www.socioambiental.org. Acesso em: 18 ago. 2009.

AMARAL, Wagner R. As trajetórias dos estudantes indígenas nas Universidades Estaduais do Paraná: sujeitos e pertencimentos. 2010, 586f. Tese (Doutorado em Educação) - Universidade Federal do Paraná, Curitiba, 2010.

CARDOSO DE OLIVEIRA, Roberto. O índio e o mundo dos brancos. São Paulo: Difusão Europeia do Livro, 1964.

CARDOSO DE OLIVEIRA, Roberto. Caminhos da identidade: ensaios sobre etnicidade e multiculturalismo. São Paulo: Editora Unesp; Brasília: Paralelo 15, 2006.

CAVALCANTE, Márcio R. V. O que há de perspicácia e o que há de ingenuidade nos motivos apresentados pelos indígenas sobre a escola? In: UNIVERSIDADE FEDERAL DE MINAS GERAIS. Tabebuia: índios, pensamento e educação. Belo Horizonte: FIEI/UFMG, 2009. p. 104-113.

HALL, Stuart. A Identidade Cultural na Pós-Modernidade. Rio de Janeiro: DP\&A, 2003.

KELLY, José A. Notas para uma teoria do ”virar branco”. Mana: Revista de Antropologia Social, Rio de Janeiro, v. 11, n. 1, p. 201-234, 2005.

LANDOWSKI, Eric. As Presenças do Outro - ensaios de sociossemiótica. São Paulo: Perspectiva, 2002.

LIMA, Antonio C. de Souza; BARROSO-HOFFMANN, Maria (Org.). Seminário Desafios para uma educação superior para os povos indígenas no Brasil: políticas públicas de ação afirmativa e direitos culturais diferenciados. Rio de Janeiro: Museu Nacional/LACED, 2007.

LÓTMAN et al. Ensaios de Semiótica Soviética. Lisboa: Livros Horizonte, 1981.

LUCIANO, Gersem dos S. O Índio Brasileiro: o que você precisa sobre os povos indígenas no Brasil de hoje. Brasília: MEC-UNESCO SECAD, Coleção Educação para Todos, 2006. 
MOTA, Lúcio T. As guerras dos índios Kaingang: a história épica dos índios Kaingang no Paraná (1769-1924). Maringá: EDUEM, 1994.

TOMMASINO, Kimiye; FERNANDES, Ricardo C. Kaingang. In: INSTITUTO SOCIOAMBIENTAL. Enciclopédia dos Povos Indígenas no Brasil. 2001. Disponível em: http://www.socioambiental.org/pib. Acesso em: 16 jul. 2009.

Data de submissão: 24/04/2014

Data de aprovação: 04/08/2014 